\title{
Latihan Keseimbangan dan Stimulasi Somatosensoris Meningkatkan Keseimbangan Statis pada Penderita Diabetes Neuropati
}

\author{
Zahra Sativani \\ Jurusan Fisioterapi, Politeknik Kesehatan Jakarta I \\ email: zsativani@gmail.com
}

Received: 26-04-2019, Review: 28-05-2019, 12-07-2019, Accepted: 18-07-2019

\begin{abstract}
Abstrak
Gangguan keseimbangan pada penderita diabetes neuropati dapat disebabkan oleh disfungsi somatosensoris. Disfungsi somatosensoris dapat memicu instabilitas postural yang berdampak pada peningkatan risiko jatuh. Salah satu penyebab terjadinya disfungsi somatosensoris adalah hiperglikemia melalui mekanisme kerusakan saraf perifer. Latihan keseimbangan merupakan salah satu latihan yang dapat meningkatkan keseimbangan. Belum terdapat cukup bukti bahwa keseimbangan statis mengalami peningkatan setelah melakukan kombinasi latihan keseimbangan dan stimulasi somatosensoris pada penderita diabetes neuropati. Penelitan ini bertujuan untuk membuktikan pengaruh kombinasi latihan keseimbangan dan stimulasi somatosensoris terhadap keseimbangan statis pada penderita diabetes neuropati. Penelitian eksperimental, dilakukan di Rumah Diabetes Universitas Surabaya selama tiga minggu. Analisis data statitsik menggunakan uji analisis stastistik berbasis komputer dan uji normalitas menggunakan Shapiro-wilk. Analisis perbedaan rerata dilakukan melalui uji t berpasangan dan uji t bebas. Sebanyak dua belas responden penderita diabetes mellitus tipe dua dengan onset > 10 tahun, dipilih secara acak dan dikelompokkan. Kelompok satu $(n=6)$ mendapatkan latihan keseimbangan dan stimulasi somatosensoris selama lima kali seminggu. Kelompok dua kontrol $(\mathrm{n}=6)$ mendapatkan edukasi dua kali. Hasil penelitian Unipedal Stance Test sebelum dan sesudah perlakuan pada kelompok satu menunjukkan adanya perbedaan bermakna sedangkan elompok dua cenderung tidak berubah. Hasil uji t bebas menunjukkan bahwa terdapat perubahan signifikan pada delta UPST. dengan $p$ value 0,000. Kombinasi latihan keseimbangan dan stimulasi somatosensoris dapat
\end{abstract}

meningkatkan keseimbangan statis pada penderita diabetes neuropati.

Kata Kunci : diabetes, neuropati, keseimbangan, somatosensoris

\begin{abstract}
Impaired balance on diabetic neuropathy can be caused by somatosensory dysfunction. Somatosensory dysfunction has triggering of postural instability resulting increase risk of falling. One of the causes of somatosensory dysfunction is hyperglycemia through peripheral nerve damage mechanism. Balance exercise is the one of exercises to improve balance. However, not sufficient evidences available were measured static balance after doing balance exercises and somatosensory stimulation. This study aimed to prove the impact of balance exercise and somatosensory stimulation on static balance in diabetic neuropathy. Experimental study, 12 type II diabetic with onset > 10 years were enrolled, randomized, and divided into two groups. For three weeks, group 1 an intervention group $(n=6)$ received balance exercise and somatosensory stimulation for five days a week. Group 2 a control group (n=6) received education for two times in three weeks. The end of the period, the intervention group showed a significant improvement in static balance, $p$ value 0,000. Balance exercise and somatosensory stimulation could improve static balance in diabetic neuropathy.
\end{abstract}

Keywords : diabetic, neuropathy, balance, somatosensoris

\section{Pendahuluan}

Gangguan keseimbangan dapat disebabkan oleh adanya disfungsi somatosensoris. Disfungsi somatosensoris dapat memicu instabilitas postural yang berdampak 
pada risiko jatuh (Gu \& Dennis, 2016). Hiperglikemia merupakan salah satu penyebab terjadinya disfungsi somatosensoris melalui mekanisme kerusakan saraf perifer. Kerusakan saraf perifer meliputi gangguan sistem saraf sensoris terutama reseptor somatosensoris, motorik, dan otonom. Kerusakan reseptor somatosensoris menyebabkan gangguan pada serabut saraf sensorik kecil (tipe C) yang berkaitan dengan sensasi nyeri dan perubahan persepsi suhu. Sedangkan kerusakan saraf sensorik pada serabut saraf besar (tipe A) berkaitan dengan hilangnya sensasi sentuhan, getaran, propiosepsi, dan motor innervation pada otot-otot intrinsik kaki (Gow and Moore, 2014; Grundy, 2012). Gejala klinis tersebut baru terdeteksi setelah individu mengalami hiperglikemia lebih dari sepuluh tahun dan akan menjadi progresif setelahnya (Al-Rubeaan et al., 2015).

International Diabetes Federation (IDF) (2012) menyatakan terdapat 280 juta orang dengan impaired glucose tolerance (IGT) di dunia dan diproyeksi jumlahnya akan terus meningkat hingga mencapai 400 juta orang pada tahun 2030. Di Indonesia, proporsi toleransi glukosa terganggu (TGT) mencapai $29,9 \%$ atau 52 juta orang. Sedangkan glukosa darah puasa terganggu (GDPT) sebesar 36,6\% atau 64 juta orang (Kementrian Kesehatan RI, 2014). Diabetes neuropati merupakan komplikasi mikrovaskular yang menyerang $50 \%$ penderita diabetes mellitus (Juster-Switlyk \& Smith, 2016).

Salah satu upaya untuk pencegahan risiko jatuh pada individu yaitu dengan meningkatkan keseimbangan statis. Stimulasi somatosensoris merupakan suatu upaya mengoptimalkan fungsi reseptor sensoris terhadap rangsangan dan berperan menjaga stabilitas postural melalui kontrol terhadap goyangan tubuh/body sway. Latihan keseimbangan merupakan salah satu upaya yang dapat diberikan untuk meningkatkan keseimbangan dan kontrol postural (Sativani et al., 2017). Adanya input somatosensoris dari telapak kaki merupakan faktor penting untuk menjaga keseimbangan berdiri. Oleh karena itu, kombinasi latihan keseimbangan dan stimulasi somatosensoris perlu dilakukan.

Penelitian ini bertujuan untuk membuktikan pengaruh kombinasi latihan keseimbangan dan stimulasi somatosensoris terhadap peningkatan keseimbangan statis pada penderita diabetes neuropati.

\section{Metode Penelitian}

Desain penelitian eksperimental dengan rancangan pre and post-test with control design yang dilakukan di Rumah Diabetes Universitas Surabaya. Responden penelitian ini adalah anggota Persatuan Diabetes Indonesia (PERSADIA) di Rumah Diabetes Universitas Surabaya yang berjumlah dua belas orang dengan usia 50-65 tahun, berjenis kelamin perempuan delapan orang dan laki-laki empat orang, rutin injeksi insulin, diabetes mellitus tipe II dengan onset > 10 tahun, mampu berjalan mandiri tanpa menggunakan alat bantu seperti tripod, walker, tongkat dan kursi roda, dan bersedia menjadi responden. Kriteria eksklusi yaitu memiliki luka terbuka pada area punggung dan telapak kaki, mengalami gangguan vestibular dan gangguan visual yang tidak dapat dikoreksi dengan menggunakan kacamata. Besar sampel terpenuhi dilakukan randomisasi untuk menentukan kelompok perlakuan dan kontrol. Penentuan kelompok menggunakan teknik alokasi random yaitu setiap responden diminta mengambil nomor undian dan akan masuk ke dalam kelompok sesuai undian yang diperoleh. Kelompok perlakuan $(n=6)$ mendapatkan latihan keseimbangan dan stimulasi somatosensoris lima kali seminggu selama tiga minggu. Kelompok kontrol $(n=6)$ mendapatkan edukasi dua kali dalam tiga minggu. Setiap kelompok mendapatkan pemeriksaan sebelum dan setelah tiga minggu pemberian latihan.

Pengukuran keseimbangan statis menggunakan Unipedal Stance Test (UPST) dalam satuan detik. Pengukuran dilakukan pada posisi berdiri kemudian diperkenankan untuk memilih tungkai yang akan diukur. Responden diminta untuk mengangkat tungkai dengan kondisi mata terbuka dan dilanjutkan dengan mata tertutup. Posisi kedua tangan masingmasing bersilangan di depan dada dan direntangkan. Responden dinyatakan berhasil bila mampu mempertahankan posisi selama empat puluh lima detik, tungkai diangkat tidak menyentuh lantai, dan lengan tidak berpegangan pada instruktur. Pengukuran dilakukan sebanyak 
tiga kali untuk masing-masing kondisi dan diambil nilai terbaik.

Latihan keseimbangan dan stimulasi somatosensoris dilakukan lima kali seminggu selama tiga minggu. Satu sesi latihan dilakukan selama lima puluh lima menit (pemanasan lima menit, latihan inti empat puluh lima menit, dan pendinginan lima menit) (Fall Prevention Center of Excellence, 2010; Rojhani-Shirazi, et al., 2016).

Latihan keseimbangan menggunakan metode ball training protocol Rojhani-Shirazi (2016) yang dikombinasikan dengan gerakan dari Fall Prevention Center of Excellence, California State University. Latihan dilakukan secara berkelompok pada dua posisi yaitu duduk (di kursi dan swiss ball) dan berdiri serta beralas rumput sintetis sebagai media stimulasi somatosensoris. Kelompok kontrol mendapatkan edukasi berupa pengetahuan tentang diabetes dan diabetes neuropati, perawatan kaki dan latihan yang dapat dilakukan di rumah. Edukasi dilakukan dua kali dalam tiga minggu.

Analisis statitsik menggunakan uji analisis stastistik berbasis komputer. Uji analisis deksriptif menghitung niai rerata dan simpangan deviasi. Kemudian dialkukan uji normalitas menggunakan Shapiro-wilk. Analisis perbedaan rerata dilakukan melalui uji $\mathrm{t}$ berpasangan dan uji $\mathrm{t}$ bebas. Uji $\mathrm{t}$ berpasangan dilakukan untuk mengetahui perubahan sebelum dan sesudah latihan pada masing-masing kelompok. Nilai $\mathrm{p}<$ 0,05 menunjukkan adanya perubahan signifikan. Uji t bebas dilakukan untuk mengetahui respon antara kelompok. Respon atau delta adalah hasil post-test dikurangi hasil pre-test. Apabila hasil p $<0,05$ maka terdapat perbedaan bermakna.

Penelitian ini telah lulus uji etik di Fakultas Kedokteran Gigi Universitas Airlangga (056/HRECC.FODDM/V/2017).

\section{Hasil Penelitian}

Analisis deskriptif karakteristik subyek menggambarkan tidak ada perbedaan signifikan antara kedua kelompok pada variabel usia, berat badan, tinggi badan, indeks massa tubuh (IMT), gula darah acak (GDA) dan lama mengidap diabetes. Berdasarkan uji normalitas Shapirowilk data deskriptif karakteristik subyek berdistribusi normal ( $p>0,05)$.

Tabel 1

Rerata, simpangan deviasi dan uji normalitas karakteristik responden penelitian

\begin{tabular}{|l|c|c|c|}
\hline \multirow{2}{*}{ Variabel } & \multicolumn{2}{c|}{ Rerata \pm SD } & \multirow{2}{*}{ P } \\
\cline { 2 - 3 } & Kelompok Perlakuan $(\mathrm{n}=6)$ & Kelompok Kontrol $(\mathrm{n}=6)$ & 0,163 \\
\hline Usia (tahun) & $60,17 \pm 4,07$ & $56,83 \pm 5,74$ & 0,160 \\
\hline Berat badan $(\mathrm{kg})$ & $58,58 \pm 4,24$ & $59,50 \pm 8,61$ & 0,824 \\
\hline Tinggi badan $(\mathrm{cm})$ & $152,75 \pm 6,91$ & $158,42 \pm 9,56$ & 0,287 \\
\hline $\begin{array}{l}\text { Indeks Massa Tubuh } \\
\left(\mathrm{kg} / \mathrm{m}^{2}\right)\end{array}$ & $25,06 \pm 2,07$ & $23,64 \pm 1,90$ & 0,413 \\
\hline Gula Darah Acak $(\mathrm{mg} / \mathrm{dl})$ & $189,83 \pm 58,55$ & $202,67 \pm 69,67$ & 0,089 \\
\hline Lama diabetes (tahun) & $24,67 \pm 5,12$ & $24,17 \pm 7,16$ & \\
\hline
\end{tabular}

Tabel 1 menjelaskan bahwa penderita diabetes melitus tipe II dengan rerata usia 56-60 tahun dan rerata lama mengidap diabetes 24 tahun memiliki gejala awal komplikasi neuropati. Penelitian Parisi, et al. (2016) menyatakan prevalensi diabetes neuropati perifer terbanyak pada usia 50-59 tahun. Begitu pula dalam penelitian Dunnigan et al. (2013) menyatakan bahwa risiko diabetic foot state terjadi pada usia 45-64 tahun dengan jumlah kasus sebesar 845 (40.80\%). Lebih dari 50\% penderita diabetes usia tua dengan lama diabetes $>25$ tahun memiliki neuropati dengan gangguan pada sistem saraf perifer bagian distal pada ekstremitas bawah dan gangguan sistem sensoris yang berkontribusi dalam pengaturan kontrol postural, sebagai contoh sistem somatosensoris (Kutty \& Majid, 2013). 
Tabel 2

Perbedaan sebelum dan sesudah intervensi pada kelompok perlakuan dan kontrol menggunakan uji t berpasangan

\begin{tabular}{|c|c|c|c|}
\hline \multirow{2}{*}{ Kelompok } & \multicolumn{2}{|c|}{ Rerata \pm SD } & \multirow{2}{*}{$\mathrm{p}$} \\
\cline { 2 - 3 } & Sebelum & Sesudah & $0,000^{*}$ \\
\hline Kelompok perlakuan & $27,36 \pm 3,82$ & $43,95 \pm 1,57$ & 0,128 \\
\hline Kelompok kontrol & $30,62 \pm 4,05$ & $29,46 \pm 4,87$ & \\
\hline
\end{tabular}

*Nilai signifikan $\mathrm{p}<0,05$

Analisis perbedaan rerata menggunakan uji $t$ berpasangan menunjukkan perbedaan bermakna sebelum dan sesudah latihan keseimbangan dan stimulasi somatosensoris $(\mathrm{p}<0,05)$ pada

Tabel 3

Perbedaan sebelum dan sesudah intervensi antara kelompok perlakuan dan kontrol menggunakan uji t bebas

\begin{tabular}{|c|c|c|c|}
\hline \multirow{2}{*}{ Variabel } & \multicolumn{2}{|c|}{ Rerata \pm SD } & \multirow{2}{*}{$\mathrm{p}$} \\
\cline { 2 - 3 } & Kelompok perlakuan $(\mathrm{n}=6)$ & Kelompok kontrol $(\mathrm{n}=6)$ & \multirow{2}{*}{$0,000^{*}$} \\
\hline $\begin{array}{c}\text { Delta pengukuran } \\
\text { keseimbangan statis }\end{array}$ & $16,58 \pm 4,28$ & $-1,16 \pm 1,56$ & \\
\hline
\end{tabular}

$*$ Nilai signifikan $\mathrm{p}<0,05$

Analisis perbedaan rerata menggunakan uji $\mathrm{t}$ bebas menunjukkan perbedaan bermakna sesudah pemberian latihan keseimbangan dan stimulasi somatosensoris antara kelompok perlakuan dan kontrol dilihat dari selisih nilai keseimbangan statis menggunakan parameter Unipedal Stance Test (UPST) pada setiap kelompok $(\mathrm{p}=0,000)$.

\section{Diskusi}

Keseimbangan merupakan kemampuan tubuh mempertahankan pusat gravitasi pada bidang tumpu dalam keadaan statis atau dinamis serta melibatkan penggunaan aktivitas otot. Peningkatan keseimbangan statis setelah pemberian latihan keseimbangan dan stimulasi somatosensoris disebabkan oleh adanya integrasi kompleks antara sistem somatosensoris (visual, vestibular, propiosepsi) dan motorik dengan regulasi oleh sistem saraf pusat. Sistem sensorimotor, sistem saraf pusat, dan processing component terlibat dalam menjaga keseimbangan kerja sendi ketika tubuh bergerak (functional joint stability). Komponen statis merupakan artikulasi antara ligament, kapsul sendi, kartilago, friction, dan geometri tulang. Latihan keseimbangan dan stimulasi somatosensoris yang diberikan terus menerus dan melibatkan banyak gerakan menyebabkan kelompok perlakuan $(\mathrm{p}=0,000)$. Berbeda dengan kelompok kontrol yang tidak menunjukkan adanya perbedaan bermakna $(\mathrm{p}=0,128)$. kerja komponen statis yang terjadi berulangulang sehingga feedback pada sistem neuromuskular akan tetap berlangsung (Abrahamova and Hlavacka, 2008; Rogers, et al., 2005; Raju, 2012).

Latihan keseimbangan yang diberikan menggunakan media ball training. Ball training merupakan metode latihan keseimbangan yang melatih kerja otot perut/core work dan kontrol postural. Core work dan kontrol postural merupakan salah satu faktor yang mempengaruhi bidang tumpu (base of support) dan terlibat dalam menentukan posisi pusat gravitasi (center of gravity). Pusat gravitasi/center of gravity (COG) berperan dalam mendistribusikan massa benda secara merata dan menjaga tubuh tetap berada dalam keadaan seimbang. Pada manusia, titik pusat gravitasi dipengaruhi oleh perubahan berat badan, sehingga dapat dikatakan pusat gravitasi dapat berpindah sesuai dengan perubahan berat. Sedangkan bidang tumpu/base of support (BOS) merupakan bagian tubuh yang berhubungan dengan permukaan tubuh. Tubuh dalam keadaan seimbang bila garis gravitasi berada tepat di bidang tumpu. Semakin luas bidang tumpu maka semakin tinggi stabilitas tubuh. Selain itu, semakin dekat bidang tumpu dengan pusat gravitasi maka stabilitas tubuh semakin tinggi. 
Pada pengukuran keseimbangan statis yang diukur dengan UPST, posisi subyek berdiri menggunakan satu kaki. Gerakan tersebut menguji kontrol postural dalam bertahan pada posisi diam, sehingga peningkatan hasil pada tes ini untuk kelompok 1 membuktikan bahwa komponen kerja statis mulai terbangun (Rogers, et al., 2005; Raju, 2012).

Hasil peningkatan keseimbangan statis pada penelitian ini sesuai dengan penelitian yang dilakukan oleh Allet et al. (2010) yaitu bahwa setelah pemberian balance exercise pada penderita DM tipe II terjadi perubahan signifikan pada sway index dan dynamic balance test. Selain itu efek kronik balance exercise tetap terlihat ketika dilakukan pemeriksaan performance-oriented mobility assessment (POMA) dan dynamic balance setelah dilakukan follow up 6 bulan kemudian. Penelitian RojhaniShirazi et al. (2016) juga menyatakan bahwa terdapat peningkatan keseimbangan berdasarkan nilai Berg Balance Scale (BBS).

\section{Kesimpulan}

Kombinasi latihan keseimbangan dan stimulasi somatosensoris dapat meningkatkan keseimbangan statis pada penderita diabetes neuropati.

\section{Saran}

Penelitian lebih lanjut dibutuhkan dengan jumlah subyek yang lebih besar untuk melihat pengaruh latihan keseimbangan dan stimulasi somatosensoris terhadap prevalensi jatuh dan kemampuan aktivitas fisik penderita diabetes neuropati. Selain itu juga perlu dilakukan follow up beberapa bulan setelah latihan dan stimulasi dilakukan untuk mengetahui efek jangka latihan. Selain itu, pemeriksaan kekuatan otot juga dapat dipertimbangkan sebagai salah satu pemeriksaan sebelum dan sesudah.

\section{Daftar Pustaka}

Abrahamova, D, Hlavacka, F, 2008, Age-related changes of human balance during quite stance. Physiological Research Institute of Physiology. 6(57):957-64. https://www.researchgate.net/publication/5794795_Ag e-

$\underline{\text { Related_Changes_of_Human_Balance_during_Quiet_ }}$ Stance

Allet, L, Armand, S, De Bie, R A, Golay, A, Monnin, D, Aminian, K, De Bruin, E D, 2010, The gait and balance of patients with diabetes can be improved: A randomised controlled trial. Diabetologia, 53(3), 458-466. http://dx.doi.org/10.1007/s00125-009$\underline{1592-4}$

Dunnigan, S. K. Ebadi, H. Breiner, A. Katzberg, H. D. Lovblom, L. E. Perkins, B. A. Bril, V. 2013. Conduction Slowing in Diabetic Sensorimotor Polyneuropathy. Diabetes Care.36(11):3684-90. http://dx.doi.org/10.2337/dc13-0746

Fall Prevention Center of Excellence. 2010. Balance and Mobility Exercises for Physical Classes. California State of University.

Gow, D. Moore, P. 2014. Assessing Diabetic Peripheral Neuropathy in Primary Care. Best Practice Journal. (61): 36-47. http://www.bpac.org.nz/BPJ/2014/june/docs/BPJ61diabetic-peripheral-neuropathy.pdf.

Grundy, S M, 2012, Pre-diabetes, metabolic syndrome, and cardiovascular risk. Journal of the American College of Cardiology, 59(7),635-643. https://doi.org/10.1016/i.jacc.2011.08.080

Gu, Y. Dennis, S. M. 2016. Are Falls Prevention Programs Effective at Reducing the Risk Factors for Falls in People with Type-2 Diabetes Mellitus and Peripheral Neuropathy: A Systematic Review with Narrative Syntehesis Medline (OVID). Journal of Diabetes and its Complications. http://dx.doi.org/10.1016/j.jdiacomp.2016.10.004

International Diabetes Foundation 2012, About Diabetes, diakses pada 9 Juli 2019, https://idf.org/52-aboutdiabetes.html

Juster-Switlyk, K. Smith, A. G. 2016. Updates in Diabetic Peripheral Neuropathy. F1000 Research. http://dx.doi.org/10.12688/f1000research.7898.1.

Kementerian Kesehatan RI. 2014. Waspada Diabetes: Eat Well, Life Well. Pusat Data dan Informasi Kementerian Kesehatan RI.

Kutty, N. Majid, N. 2013. Effects of Multisensory Training on Balance and Gait in Persons with Type 2 Diabetes: A Randomized Controlled Trial. Disabbility CBR \& Inclusive Development. 24(2): 79-91. http://dx.doi.org/10.5463/DCID.v24i2.206.

Parisi, M. C. et al. 2016. Baseline Characteristic and Risk Factors for Ulcer Amputation and Severe Neuropathy in Diabetic Foot at Risk: The BRAZUPA Study. Diabetology \& Metabolic Syndrome. 8: 25. http://dx.doi.org/10.1186/s13098-016-0126-8.

Raju, Y. 2012. Maintenance of Balance and Rehabilitation in the Elderly. Medicine Update Journal Vol. 22.

Rogers JM, Daly JJ, Hogan N, Perepezko EM, Krebs HI, Goyal KS, Dohring ME, Fredrickson E, Nethery J, Ruff RL. 2005. Response to upper-limb robotics and functional neuomuscular stimulation following stroke. Journal of Rehabilitation Research and Development. 42(6): 723-736

Rojhani-Shirazi, Z. Barzintaj, F. Salimifard, M. R. 2016. Comparison the Effects of Two Types of Therapeutic Exercises Frenkele vs. Swiss Ball on the Clinical Balance Measures in Patients with Type II Diabetic Neuropathy. Diabetes \& Metabolic Syndrome: 
Clinical Research \& Reviews. 8-11. http://linkinghub.elsevier.com/retrieve/pii/S18714021 1631746.

Sativani, Z. Purwanto, B. Utomo, D. N, 2017, Efek Latihan Keseimbangan dan Stimulasi Somatosensoris Terhadap Respon Somatosensoris Pada Penderita Diabetes Neuropati. Proceeding Surabaya International Health Conference 2017. http://journal.unusa.ac.id/index.php/sihc/article/view/3 40 . 